\title{
Late antenatal care initiation: the case of public health centers in Ethiopia
}

\author{
Solomon Weldemariam" ${ }^{*}$, Ashenafi Damte ${ }^{2}$, Kedir Endris², Melba C. Palcon², Kidisti Tesfay², Almaz Berhe², \\ Tsige Araya ${ }^{2}$, Hadgay Hagos ${ }^{2}$ and Haftom Gebrehiwot ${ }^{2}$
}

\begin{abstract}
Objective: The aim of this study was to determine the magnitude of late initiation of antenatal care visit and associated factors among antenatal care follow up women in Tselemte district health facilities. The data were obtained at health facilities level in a single survey within 1 month and there is no continuation part of this study or previously published part elsewhere.

Results: $60.5 \%$ of women were late to initiate the first antenatal care visit. Time constraint with household activity (24.4\%), distance to health center (17.2\%) and fear of long waiting time in health facility (19.5\%) were among the reasons mentioned for late initiation of antenatal care visit. Monthly income $\leq \$ 21$ (400 ETB) (AOR $=4.54,95 \% \mathrm{Cl} 1.07$, 19.33), women who accompanied by their husband during antenatal care visit ( $A O R=6.99,95 \% \mathrm{Cl} 2.82,17.31$ ), who had information access on antenatal care $(\mathrm{AOR}=4.85,95 \% \mathrm{Cl} 1.88,12.50)$ and distance from home to health center $(\mathrm{AOR}=5.44,95 \% \mathrm{Cl} 1.54,19.25)$ were significantly associated factors with late initiation of antenatal care visit. This study illustrated that large number of pregnant women still late for first antenatal care visit. Husband involvement and health education about the timing of antenatal care initiation should be encouraged in all aspects of maternal care.
\end{abstract}

Keywords: Late antenatal care initiation, Public health centers, Tselemte district, Ethiopia

\section{Introduction}

Antenatal care (ANC) is a special care given for women during pregnancy and it is regarded as the cornerstone for improving peri-natal outcomes [1, 2]. The World Health Organization (WHO) focused antenatal care (FANC) model recommends a minimum of four ANC visit and the first visit to be within the first 16 weeks of gestation $[3,4]$. Several studies illustrated that early and frequent ANC follow up provides an opportunity for institutional delivery $[5,6]$. A pregnant women with untreated syphilis, $70-100 \%$ of their babies would be acquired this infection congenitally and one-third would end up with stillbirths $[3,4,7]$. It has been estimated that $25 \%$ of maternal deaths and $15 \%$ of life threatening complications occur during the prenatal period [7].

\footnotetext{
*Correspondence: mikiass1708@gmail.com

${ }^{1}$ Department of Midwifery, College of Health Sciences, Mekelle University, Mekelle, Ethiopia

Full list of author information is available at the end of the article
}

In developing countries, majority of pregnant women start the first ANC visit by their 2nd or 3rd trimester of pregnancy [8]. Hypertension and hemorrhage during pregnancy accounts' for one-third to half of maternal deaths [7]. Demographic Health Servey findings showed that the variation in timing of ANC booking across subSaharan African remains notable. For example, only 11\% of women in Ethiopia, $16 \%$ in Nigeria, 55\% in Ghana, $12 \%$ in Kenya and 15\% in Malawi have started ANC follow up by their first 12 weeks [9]. Several studies in Ethiopia report that late entry to ANC visit associated with socio-demographic variables, parity, media exposure, lack of social support, and cultural factors even though these studies are not consistent $[3,4,10,11]$. The Ethiopian government has built an impressive work to improve the health of mothers through health extention workers $[7,12,13]$. There is also an improvement in ANC booking time from $6 \%$ in 2005 to $11 \%$ in 2011 [14]. Despite of these improvements, still maternal mortality ratio (MMR) is unacceptable in Ethiopia (676/100,000 births) 
[14]. As far as our knowledge, studies related to timing of ANC visit are scarce in the study region.

\section{Main text \\ Methods \\ Study setting}

Institution based cross-sectional study was conducted in Tselemti district, North-West Tigray Ethiopia, from Feburary 5 to March 3/2014. It is located to the Northern part of Ethiopia, about $1158 \mathrm{~km}$ from Addis Ababa and 375 from Mekelle the capital city of Tigray Region. According to 2007 central Statistics, Tigray region has an estimated total population of $4,316,988$, of which $2,190,523$ were female [15].

\section{Sample size and sampling techniques}

A single population proportion formula $(\mathrm{n}=(\mathrm{Z} \alpha / 2) 2 \mathrm{P}$ $(1-\mathrm{P}) / \mathrm{d} 2)$ was used to estimate the required sample size. The following assumption were made while calculating the sample size. Population proportion of women who start ANC visit late after 16 weeks of gestation assumed to be $67.3 \%$ [16], 95\% confidence interval, $5 \%(\mathrm{~d}=0.05)$ margin of error, and expected non-response rate $10 \%$. Overall, we recruited a sample size of 372 respondents. There were seven public health centers in this district and all of them were included in this study. Proportional to population size (PPS) allocation technique was used to allocate sample size to each health center. Systematic sampling technique was used to recruit eligible respondents. The value of "kth" was 2 for the health centers and 3 for the primary hospital. Registration of the clients at ANC was used as sampling fram and lottery method was used to select the first participant.

\section{Inclusion and exclusion criteria}

Being pregnant mother and reside in the study area at least for 6 month were used as eligibility criteria to include in this study. Women who have unknown gestational age were excluded from this study.

\section{Data collection tool and procedures}

A semi structured questionnaire was adapted in English from published literatures and translated into Tigrigna language (local language). A Pretest was conducted among 10\% (38 women) of the sample size in Dabaguna Health Center outside of the study area which has similar socio-demographic characteristics as the study district. Four female diploma midwives involved in data collection after having 2 days training and data were collected through face to face interview. The overall supervision was carried out by the principal investigator and 2 supervisors daily. Ethical approval was obtained from Institutional Ethical Review Board (IERB) of Mekelle University,
College of Health Sciences. A letter of permission was obtained from Tigray Regional Health Bureau to Tselemti district Health Bureau then to respective Health Facilities. Informed written consent was taken from each study participants and for participants below 18 years old was taken from their mothers/fathers.

\section{Statistical analysis}

Data were cleaned and entered into SPSS version 20.0 software for processing and analysis. Descriptive statistics such as percent, mean and standard deviation were computed. Bivariate and multivariable logistic regression analysis were computed. Odds ratio with $95 \%$ CI was computed to ascertain the association between covariate and dependant variables. Variables that have P-value of $<0.2$ at bivariate analysis were exported into multivariable logistic regression analysis to control possible confounding factors. Statistical test at P-value of $<0.05$ were considered as cut off point to determine statistical significance.

\section{Results}

Socio-demographic characteristics

Out of 372 recruited respondents, 365 of them were responded completely, giving a response rate of $98.1 \%$. The mean age of the respondents was 24.8 years $(\mathrm{SD} \pm 5.8)$. Almost, 352 (96.4\%) of respondents were Tigray in ethnicity and 350 (95.9\%) Orthodox Christian. Regarding occupation, 251 (68.8\%) husbands were farmer, 43 (11.8\%) civil servant, 36 (9.9\%) merchant and the rest were daily laborer by occupation (Table 1 ).

Reproductive and perception of ANC service characteristics Out of 365 respondents, 269 (73.7\%) were multi-gravida and 96 (26.3\%) were primi-gravida. Almost all respondents, 357 (97.8\%) were perceived that antenatal care check-up is essential to the health of mother and the fetus. One hundred fifty-two (41.6\%) and 78 (21.4\%) respondents perceived that 4 and $>4$ ANC visits are mandatory during pregnancy respectively. Majority, 285 (78.1\%) of respondents were inform their pregnancy to their husbands and the rest to their relatives and friends initially (Table 2). Majority of respondents (92.9\%) reach the health center on foot and $242(66.3 \%)$ had not radio or Television at home.

\section{Past history of ANC service utilization}

Among the multi-gravida respondents, 192 (71.4\%) of them had at least one history of ANC visit, of which 46.4\% within the recommended time. About, 135 (70.3\%) of respondents were receive information when to start ANC visit from health service providers and 17 (6.3\%) of them had history of pregnancy complications. One 
Table 1 Socio-demographic characteristics among pregnant mothers attending ANC service in Tselemte district, Tigray, Ethiopia, March 2014

\begin{tabular}{|c|c|c|}
\hline Variables & $\begin{array}{l}\text { Frequency } \\
(n=365)\end{array}$ & Percent (\%) \\
\hline \multicolumn{3}{|l|}{ Age (years) } \\
\hline $15-19$ & 73 & 20 \\
\hline $20-24$ & 108 & 29.6 \\
\hline $25-29$ & 89 & 24.4 \\
\hline $30-34$ & 65 & 17.8 \\
\hline $35-39$ & 30 & 8.2 \\
\hline \multicolumn{3}{|c|}{ Marital status of the mother } \\
\hline Married & 351 & 96.2 \\
\hline Divorced & 4 & 1.1 \\
\hline Separated & 3 & 0.8 \\
\hline Cohabitated & 7 & 1.9 \\
\hline \multicolumn{3}{|l|}{ Residence } \\
\hline Urban & 120 & 32.9 \\
\hline Rural & 245 & 67.1 \\
\hline \multicolumn{3}{|l|}{ Educational status } \\
\hline No formal education & 214 & 58.6 \\
\hline Elementary (1-8) & 99 & 27.1 \\
\hline Secondary (9-12) & 34 & 9.3 \\
\hline Higher education & 18 & 4.9 \\
\hline \multicolumn{3}{|l|}{ Occupational status } \\
\hline House wife & 100 & 27.4 \\
\hline Farmer & 202 & 55.3 \\
\hline Civil servant & 20 & 5.5 \\
\hline Business women & 28 & 7.7 \\
\hline Daily laborer & 15 & 4.1 \\
\hline \multicolumn{3}{|c|}{ House hold monthly income(ETB) } \\
\hline$\leq 400$ & 94 & 25.8 \\
\hline $401-600$ & 81 & 22.2 \\
\hline $601-1000$ & 102 & 27.9 \\
\hline$>1000$ & 88 & 24.1 \\
\hline \multicolumn{3}{|l|}{ Husband education } \\
\hline No formal education & 159 & 43.6 \\
\hline Elementary & 143 & 39.2 \\
\hline Secondary & 30 & 8.2 \\
\hline Higher education & 33 & 9 \\
\hline
\end{tabular}

hundred twelve (58.3\%) of respondents had waiting time below $1 \mathrm{~h}, 53(27.6 \%)$ between 1 and $2 \mathrm{~h}$ and the rest $>2 \mathrm{~h}$ in first visit.

\section{Magnitude of late ANC initiation and reason for late booking}

Among the total study respondents, 221 (60.5\%) of them were start their ANC follow up late (after 16 weeks of gestation). One-fourth (25.5\%) of respondents initiated their ANC visit in first trimester, $67.8 \%$ in second
Table 2 Reproductive and perception of respondents characteristics among pregnant mothers attending ANC service in Tselemte district, Tigray, Ethiopia, March 2014

\begin{tabular}{|c|c|c|}
\hline Variables & $\begin{array}{l}\text { Frequency } \\
(n=365)\end{array}$ & Percent (\%) \\
\hline \multicolumn{3}{|l|}{ Parity $(\mathrm{N}=365)$} \\
\hline Nulliparous & 96 & 26.3 \\
\hline$\geq 1$ & 269 & 73.7 \\
\hline \multicolumn{3}{|l|}{ History of abortion $(\mathrm{N}=365)$} \\
\hline No & 334 & 91.5 \\
\hline Yes & 31 & 8.5 \\
\hline \multicolumn{3}{|l|}{ History of still birth $(\mathrm{N}=365)$} \\
\hline No & 339 & 92.9 \\
\hline Yes & 26 & 7.1 \\
\hline \multicolumn{3}{|c|}{ Means of diagnosing pregnancy $(\mathrm{N}=365)$} \\
\hline Missed period & 271 & 74.2 \\
\hline By urine test & 94 & 25.8 \\
\hline \multicolumn{3}{|l|}{ Who planned the $\operatorname{Px}(\mathrm{N}=365)$} \\
\hline Wife & 1 & 0.3 \\
\hline Husband & 12 & 3.3 \\
\hline Both & 339 & 92.9 \\
\hline Neither & 13 & 3.6 \\
\hline \multicolumn{3}{|c|}{ Received advice when to start ANC for current $P_{X}(N=365)$} \\
\hline No & 149 & 40.8 \\
\hline Yes & 216 & 59.2 \\
\hline \multicolumn{3}{|c|}{ Source of Information for ANC $(N=365)$} \\
\hline Women development army & 66 & 30.6 \\
\hline Health extension workers & 64 & 29.6 \\
\hline Husbands and & 51 & 23.6 \\
\hline Other family members & 35 & 16.3 \\
\hline \multicolumn{3}{|l|}{ Decision maker $(\mathrm{N}=365)$} \\
\hline Joint decision with spouse & 179 & 49 \\
\hline Themselves & 104 & 28.5 \\
\hline Husband & 53 & 14.5 \\
\hline Their relatives & 29 & 8 \\
\hline
\end{tabular}

trimester, and $6.9 \%$ in third trimester. Time constraint with household activity (24.4\%), distance to health center (17.2\%), perceived they were save (19.5\%), unawared of pregnancy $(7.2 \%)$, not perceived benefit $(10 \%)$, Perceived the right time $(5 \%)$, negligence $(5.9 \%)$, getting service from HEWs $(8 \%)$, fear of long waiting time $(1.4 \%)$ and unwanted pregnancy $(1.4 \%)$ were the reasons mentioned for late booking.

Factors associated with late initiation of first ANC visit The odds of late ANC initiation was 4.5 among ANC visitors who had monthly house hold income of $\leq \$$ 21(400 ETB) when compared to women with monthly house hold income of $>\$ 52(1000 \mathrm{ETB})(\mathrm{AOR}=4.54$, $95 \%$ CI 1.07, 19.33). The odds of late ANC initiation was 
Table 3 Factors associated with late first ANC visit among pregnant mothers attending ANC service in Tselemte Woreda, Tigray, Ethiopia, March 2014

\begin{tabular}{|c|c|c|c|c|}
\hline \multirow[t]{2}{*}{ Variables } & \multicolumn{2}{|c|}{ Delay ANC visit } & \multirow[t]{2}{*}{ Crude OR (CI 95\%) } & \multirow[t]{2}{*}{ Adjusted OR (Cl 95\%) } \\
\hline & No n (\%) & Yes n (\%) & & \\
\hline \multicolumn{5}{|l|}{ Educational status $\mathrm{N}=365$} \\
\hline Illiterate & $67(31.3)$ & $147(68.7)$ & $2.28(1.48,3.51)$ & $2.39(0.79,7.21)$ \\
\hline Literate & $77(51.0)$ & $74(49.0)$ & 1 & 1 \\
\hline \multicolumn{5}{|l|}{ Occupational status $\mathrm{N}=365$} \\
\hline House wife & $44(44)$ & $56(56)$ & $1.94(0.96,3.91)$ & $0.43(0.10,2.18)$ \\
\hline Farmer & $58(28.7)$ & $144(71.3)$ & $3.79(1.97,7.29)$ & $0.23(0.03,1.54)$ \\
\hline Civil servant and merchant & $29(60.4)$ & $19(39.6)$ & 1 & 1 \\
\hline \multicolumn{5}{|c|}{ House hold monthly income in ETB N $=365$} \\
\hline$\leq 400$ & $27(28.7)$ & $67(71.3)$ & $3.12(1.69,5.76)$ & $4.54(1.07,19.33)^{*}$ \\
\hline $401-600$ & $27(33.3)$ & $54(66.7)$ & $2.51(1.35,4.69)$ & $3.40(0.77,15.12)$ \\
\hline $601-1000$ & $41(40.2)$ & $61(59.8)$ & $1.87(1.05,3.33)$ & $1.47(0.38,5.67)$ \\
\hline$>1000$ & $49(55.7)$ & $39(44.3)$ & 1 & 1 \\
\hline \multicolumn{5}{|l|}{ Parity $N=365$} \\
\hline Nulliparous & $47(48)$ & $51(52)$ & 1 & 1 \\
\hline$\geq 1$ & $97(36.3)$ & $170(63.7)$ & $1.62(1.01,2.58)$ & $0.52(0.05,5.92)$ \\
\hline \multicolumn{5}{|l|}{ Number of child alive $N=365$} \\
\hline No child & $57(49.6)$ & $58(50.4)$ & 1 & 1 \\
\hline 01-Feb & $45(34.1)$ & $87(65.9)$ & $1.90(1.14,3.17)$ & $6.56(0.56,76.29)$ \\
\hline$\geq 3$ & $42(35.6)$ & $76(64.4)$ & $1.78(1.05,3.01)$ & $0.95(0.09,10.52)$ \\
\hline \multicolumn{5}{|c|}{ Husband accompany to $\mathrm{HC} \mathrm{N}=365$} \\
\hline No & $56(27.2)$ & $150(72.8)$ & $3.32(2.14,5.15)$ & $6.99(2.82,17.31)^{*}$ \\
\hline Yes & $88(55.3)$ & $71(44.7)$ & 1 & 1 \\
\hline \multicolumn{5}{|c|}{ Received advice on time of booking for index $P_{x} N=216$} \\
\hline No & $31(25.6)$ & $90(74.4)$ & $3.51(1.98,6.24)$ & $4.85(1.88,12.50)^{*}$ \\
\hline Yes & $52(54.7)$ & $43(45.3)$ & 1 & 1 \\
\hline \multicolumn{5}{|c|}{ Time taken to health center $(\mathrm{min}) \mathrm{N}=339$} \\
\hline$<60$ & $79(62.2)$ & $48(37.8)$ & 1 & 1 \\
\hline $60-120$ & $20(39.2)$ & $31(60.8)$ & $2.55(1.31,4.97)$ & $1.12(0.25,5.05)$ \\
\hline$>120$ & $30(18.6)$ & $131(81.4)$ & $7.19(4.21,12.27)$ & $5.44(1.54,19.25)^{*}$ \\
\hline
\end{tabular}

* Significantly associated at $\mathrm{P}<0.05$

6.99 among ANC visitors yet not accompanied by their husband to health center as compared to their counter parts $(\mathrm{AOR}=6.99,95 \% \mathrm{CI} 2.82,17.31)$. Mothers who lack information when to start ANC follow up was 4.85 more likely to start ANC follow up late compared to their counter parts (AOR $=4.85,95 \%$ CI 1.88, 12.50). The likelihood of late ANC initiation was 5.44 among ANC attendees who walk more than $2 \mathrm{~h}$ to arrive health center than those who arrive at less than an hour walk $(\mathrm{AOR}=5.44,95 \%$ CI 1.54, 19.25) (Table 3).

\section{Discussion}

Despite of WHO recommendation that the first ANC visit to be within the first 16 weeks of gestation, high proportion of women were late. The current estimate is higher when compared to previous report from Addis Ababa, the capital city of Ethiopia, where $37.3 \%$ of women were start their first ANC visit late [17]. This might be due to the socio-demographic differences between these two regions. Health service accessibility, media exposure and educational status of the community might be in good position in Addis Ababa compared to the current study setting. However, the current finding is slightly lowered compared to finding from Mekelle (Ethiopia), where $67.3 \%$ of women were start their first ANC visit late [16]. The observed difference might be due to a relative good community sensitization and mobilization in utilizing maternal health service than ever by the health sector. 
Women who have monthly income of less than 21 dollar more likely to present themselves late for first ANC visit. In Ethiopia, maternal health service are given free of charge however women may need money for food, transportation and for some laboratory investigation and drugs that are not available in public health centers. Even some women might not awarded the availability of free ANC service. Similar findings has been reported from Holeta (Ethiopia), and Ghana whereby mothers with house hold income of less than 23 USD were more likely to present late compared to women with house hold income of above 57 USD $[18,19]$.

The present study demonstrated that women who did not accompany by their husband during ANC follow up were more likely to present late for first visit compared to their counter parts. This is possibly due to the facts that in Ethiopia the husband is usually more influential, economically empowered and socially accepted than women. The late booking therefore is likely to be attributed to the lack of financial support or lack of encouragement from partners which could discourage women from seeking early ANC services. Similar findings from Mekelle and Hadya (Ethiopia) and Tanzania support the current finding $[5,8,20]$. Women who were not informed about the timing of ANC initiation were more likely to present late when compared to their counterparts. This might be, information is vital for development of health seeking behaviour timely. This finding was in line with the finding reported from Addis Ababa and Mekelle (Ethiopia) $[16,17]$. Women who walked more than $2 \mathrm{~h}$ on foot to access the health facility were more likely to initiate ANC visit late compared to those who walked less than an hour. Distance is a significant factor in many studies from Africa. For example, a study done in Zambia, Hadya and Yem (Ethiopia) [20-22] were consistent with the current finding. The possible explanation might be most respondents of this study were reside in mountainous areas with poor infrastructure, and lack of transportation with high costs for transportation.

\section{Conclusion and recommendation}

The current finding illustrat that highest proportion of women in the study area still late for first ANC visit which in turn implies that many women are at risk of several obstetric complication. Socio-demographic variables still playing a great role in hindering maternal health service utilization.

Midwives, and other health cadres should strengthen the sensitization and mobilization of mothers on the importance of timely initiation of ANC services. Regional Health office also should open mobile clinics and home care visits program to reach those mothers disadvantaged due to geographical barrier. Husband involvement during ANC service follow up should be encouraged by midwives.

\section{Limitation}

Since this study conducted in one district health facilities, the findings might not be generalizable to the entire community in the region. Recall bias might be there since gestational age was determined based on the women memory.

\section{Additional file}

Additional file 1. An English version questionnaire used to measure this findings and it was developed from different published literatures and adjusted contextually.

\section{Abbreviations}

ANC: antenatal care; WHO: World Health Organization; WDA: women development armey; HEWs: health extension workers; USD: USA dollar.

\section{Authors' contributions}

SW, AD, KE and MP designed the study. SW prepared the proposal, obtained the data, analyzed, interpreted and obtained fund. $H G, A D, K E, M P, K T, A B, T A$, and $\mathrm{HH}$ participated in analysis, reviewed and commented critically the entire document from inception to end. SW prepared the first draft of this manuscript. All authors read and approved the final manuscript.

\section{Author details}

${ }^{1}$ Department of Midwifery, College of Health Sciences, Mekelle University, Mekelle, Ethiopia. ${ }^{2}$ Department of Nursing, College of Health Sciences, Mekelle University, Mekelle, Ethiopia.

\section{Acknowledgements}

We would like to thank Mekelle University CHS for its financial support, department of Nursing for its academic excellence; I thank, to Tselemti district Health Bureau and participants of this study for their precious time.

\section{Competing interests}

The authors declared that they have no competing interests.

\section{Availability of data and materials}

All data generated or analyzed during this study were included in this article and the data which supports this findings will be provided on request from the corresponding if needed. And the questionnaire is submitted as Additional file 1.

\section{Consent for publication}

Not applicable.

\section{Ethics approval and consent to participate}

Ethical approval was obtained from Institutional Ethical Review Board (IERB) of Mekelle University, College of Health Sciences. A letter of permission was obtained from Tigray Regional Health Bureau to Tselemti district Health Bureau then to respective Health Facilities. Informed written consent was taken from each study participants and for participant below 18 years old was taken from their mothers/fathers. The information provided by each respondent was kept confidential anonymously.

\section{Funding}

This work has been funded by Mekelle University as for M.Sc. thesis fulfillment and department of Nursing was involved in the project through monitoring and evaluation of the work. But this organization did not involve in designing, analysis, critical review of its intellectual content and preparation of manuscript. 


\section{Publisher's Note}

Springer Nature remains neutral with regard to jurisdictional claims in published maps and institutional affiliations.

Received: 9 June 2018 Accepted: 25 July 2018

Published online: 06 August 2018

\section{References}

1. Wang W, Soumya A, Shanxiao W, et al. Levels and trends in the use of maternal health services in developing country. DHS comparative reports. Calverton: ICF Macro; 2011.

2. Tshabalala FM, et al. Utilization of antenatal care and prevention of mother-to-child transmission of HIV services, M.Sc. thesis. Department of health study, South Africa University; 2012.

3. DMPS, WHO. Standards for maternal and neonatal care: provision of effective antenatal care. Geneva: IMPAC; 2008. http://www.who.int/repro ductivehealth/publications/maternal_perinatal_health/effective_anten atal_care.pdf. Accessed 25 Nov 2013.

4. Kisuule I, Kaye DK, Najjuka F, Sematimba SK, Arinda A, et al. Timing and reasons for coming late for the first antenatal care visit. BMC pregnancy and childbirth. 2013. https://doi.org/10.1186/1471-2393-13-121.

5. Gross K, Alba S, Glass TR. Timing of antenatal care for adolescent and adult pregnant women in south-eastern Tanzania. BMC Preg Childbirth. 2013. https://doi.org/10.1186/1471-2393-13-121.

6. Garrido GG. The impact of adequate prenatal care in a developing country: testing the WHO recommendations. Los Angeles: University of California; 2009. https://escholarship.org/uc/item/1c86q94h. Accessed 3 Aug 2018.

7. Lincetto O, Mothebesoane-Anoh S, Gomez P, et al. Antenatal care: opportunities for Africa's newborns. 2008. http://www.who.int/pmnch/media/ publications/aonsectionllI_2.pdf. Accessed 3 Aug 2018.

8. Oladokun A, Oladokun RE, Morhason-Bello I, Bello AF, Adedokun B. Proximate predictors of early antenatal registration among Nigerian pregnant women. Ann Afr Med. 2010;9(4):222-5. https://doi. org/10.4103/1596-3519.709.

9. Pell C, Meñaca A, Were F, Nana AA, Chatio S, et al. Factors affecting antenatal care attendance: results from qualitative studies in Ghana, Kenya and Malawi. PLoS ONE. 2013;8(1):e53747.

10. Pacagnella RC, Cecatti JG, Osis MJ, Souza JP. The role of delays in severe maternal morbidity and mortality: expanding the conceptual framework. Reprod Health Matters. 2012;20(39):155-63.
11. Solarin I, Black V. They told me to come back: women's antenatal care booking experience in inner-city Johannesburg. Matern Child Health J. 2013:17(1):359-67.

12. Federal democratic republic of Ethiopia ministry of health. Health sector development programme IV. Addis Ababa, Ethiopia; 2011. http://www. nationalplanningcycles.org/sites/default/files/country_docs/Ethiopia/ ethiopia_hsdp_iv final_draft_2010 -2015.pdf. Accessed 3 Aug 2018.

13. Koblinsky M, Tain F, Gaym A. Responding to the maternal health care challenge: the Ethiopian health extension program. Ethiop J Health Dev. 2010;24(1):105-9.

14. Central statistical agency (Ethiopia) and ICF international. Ethiopia demographic and health survey 2011. Addis Ababa, Ethiopia and Calverton, Maryland, USA; 2012. https://www.unicef.org/ethiopia/ET_2011_EDHS. pdf. Accessed 3 Aug 2018.

15. Central Statistical Agency, Population and Housing Census Report-Country-2007, Central Statistical Agency, 2010-07. http://www.csa.gov.et newcsaweb/images/documents/pdf_files/regional/Tigray.pdf. Accessed 19 Nov 2013.

16. Tekie M, Miruts G, Michael A. Factors affecting timing of first antenatal care visit at public health centers in Mekele city (M.Sc. thesis). School of public health, Mekelle university college of health sciences, Ethiopia, 2013.

17. Tariku A, Melkamu Y, Zewuditu K. Previous utilization of service does not improve timely booking in antenatal care at public health facilities in Addis Ababa. Ethiop J Health. 2010;24(3):226-31.

18. Birmeta K, Dibaba Y, Woldeyohannes D. Determinants of maternal health care utilization in Holeta town, central Ethiopia. BMC Health Serv Res. 2013;13(3):3-256

19. Manithip C, Sihavong A, Edin K, Wahlstrom R, Wessel H. Factors associated with antenatal care utilization among rural women in Lao People's Democratic Republic. Matern Child Health J. 2011;15(3):1358-60.

20. Abosse Z, Woldie M, Ololo S. Factors influencing antenatal care service utilization in Hadiya Zone. Ethiop J Health Sci. 2010;20(2):77-80.

21. Banda I, Michelo C, Hazemba A. Factors associated with late antenatal care attendance in selected rural and urban communities of the copper belt province of Zambia. Med J Zambia. 2012;39(3):30-3.

22. Tewodros B, Gmariam A, Dibaba Y. Factors affecting antenatal care utilization in Yem special woreda, Southwestern Ethiopia. Ethiop J Health Sci. 2009;19(1):45-8.
Ready to submit your research? Choose BMC and benefit from:

- fast, convenient online submission

- thorough peer review by experienced researchers in your field

- rapid publication on acceptance

- support for research data, including large and complex data types

- gold Open Access which fosters wider collaboration and increased citations

- maximum visibility for your research: over 100M website views per year

At BMC, research is always in progress.

Learn more biomedcentral.com/submissions 